\title{
Identifying probiotic characteristics of Lactobacillus crispatus isolated from the vagina
}

\author{
Sevda Er ${ }^{*}$, Ümit Can Erim², Fatma Koç³, Merih Kıvanç ${ }^{4}$
}

${ }^{1}$ Department of Medical Services and Techniques, Yunus Emre Vocational School of Health Services, Anadolu University, 26470, Eskişehir, Turkey, ${ }^{2}$ Department of Analytical Chemistry, Faculty of Pharmacy, İstanbul Medipol University, 34810, Beykoz, İstanbul, Turkey, ${ }^{3}$ Department of Microbiology, Faculty of Medicine, Istanbul Medipol University, 34810, Beykoz, Istanbul, Turkey, ${ }^{4}$ Department of Biology, Faculty of Sciences, Eskişehir Technical University, 26470, Eskişehir, Turkey

\begin{abstract}
Lactobacilli prevent overproduction of pathogenic microorganisms and contribute protecting vaginal microbiota. Many probiotic microorganisms are categorized as Lactic Acid Bacteria. In this study, it was aimed identifying probiotic characteristics of Lactobacillus crispatus isolated from the vagina of a healthy woman. For this purpose, lactic acid, hydrogen peroxide and proteolytic activity quantities and auto-aggregation, co-aggregation and hydrophobicity abilities of Lactobacillus crispatus, which has been isolated and identified by $16 \mathrm{~s}$ rRNA sequence analysis, were determined. Additionally, bile salt and acid resistance, along with antibiotic susceptibility of Lactobacillus crispatus were analyzed by the end of 3 hours. Lactic acid, hydrogen peroxide and proteolytic activity quantities of Lactobacillus crispatus were measured $2.275 \%, 0.334 \pm 0.075 \mu \mathrm{g} / \mathrm{mL}$ and $2.131 \pm 0,000 \mathrm{mg} / \mathrm{mL}$ respectively. The findings include existence of co-aggregation and auto-aggregation ability, but not hydrophobicity. By the end of 3 hours, the viability was preserved in $0.1 \%$ and $0.3 \%$ bile salt medium and, at $\mathrm{pH} 3$. L. crispatus exhibited resistance to methicillin, metronidazole, oxacillin, and sulfamethoxazole + trimethoprim, but the bacteria exhibited susceptibility to tested the other antibiotics. This study will make an important contribution to the literature about probiotic characteristics of L. crispatus and our strain isolated from the vagina might be considered as a candidate probiotic.
\end{abstract}

Keywords: Lactobacillus crispatus/probiotic. Vaginal flora. Lactic acid bacteria.

\section{INTRODUCTION}

Lactobacilli are normal inhabitants of vaginal of healthy women. Vaginal fluid contains $10^{10}$ Lactobacillus spp. per mL (Redondo-Lopez, Cook, Sobel, 1990). Albert S. Döderlein, a German physician, described bacterium isolated from a pregnant woman's vagina as Döderlein bacillus (Lepargneur, Rousseau, 2002).

Vaginal microbiota has a critical role in preserving urogenital health (Jespers et al., 2012). Lactobacilli prevent overproduction of pathogenic microorganisms and contribute protecting vaginal microbiota. Lactobacilli in the vagina compete with the pathogens in order to prevent them adhere to epithelial cells (Kaewnopparat et

\footnotetext{
*Correspondence: Sevda Er. Department of Medical Services and Techniques, Yunus Emre Vocational School of Health Services, Anadolu University, 26470, Eskişehir, Turkey. Tel no: +90 (222) 3350580/3096 / Fax no: +90 (222) 3353616. E-mail: sevdaer@anadolu.edu.tr
}

al., 2013). Previous studies suggested that Lactobacillus species bind to host epithelial cell receptors to block attachment of various urogenital pathogens including Group B Streptococcus species, Staphylococcus aureus, Gardnerella vaginalis, Neisseria gonorrhoeae, Pseudomonas aeruginosa, and Klebsiella pneumoniae to epithelial cells (Fettweis et al., 2012).

FAO/WHO described probiotics as "live microorganisms which when administered in adequate amounts confer a health benefit to the host" in 2001 (FAO/ WHO, 2001). Many probiotic microorganisms including Lactobacillus sp., Bifidobacterium sp., and Enterococcus sp. are categorized as Lactic Acid Bacteria (LAB) (Bergonzelli et al., 2005). Probiotic microorganisms have been suggested as candidate microorganisms to be included in probiotics for vaginal use (Shah, 2007). Probiotic effect is strain-specific (Paolillo et al., 2009). Therefore, it is important to establish the probiotic properties of lactic acid bacteria before the bacteria is developed as a 
probiotic product. In this study, it was aimed identifying probiotic characteristics of Lactobacillus crispatus isolated from the vagina of a healthy woman. For this purpose, lactic acid, hydrogen peroxide and proteolytic activity quantities and auto-aggregation, co-aggregation and hydrophobicity abilities of Lactobacillus crispatus, which has been isolated and identified by $16 \mathrm{~s}$ rRNA sequence analysis, were determined. Additionally, bile salt and acid resistance, along with antibiotic susceptibility of Lactobacillus crispatus were analyzed by the end of 3 hours. There are not many studies in the literature regarding the investigation of the probiotic properties of $L$. crispatus isolated from the vagina, so the work we have done will be a guide to L. crispatus and will greatly contribute to the literature.

\section{MATERIAL AND METHODS}

\section{Bacteria isolation}

In this study, bacteria isolated from the vagina of a healthy woman was inoculated with de Man, Rogosa, and Sharpe (MRS) agar) and incubated for 48 hours at $37^{\circ} \mathrm{C}$ $5 \% \mathrm{CO}_{2}$. Following incubation, gram staining and catalase test were performed. The bacteria isolate was stored in $25 \%$ glycerol, at $-80^{\circ} \mathrm{C}$.

This study was approved by İstanbul Medipol University Non-Interventional Clinical Researches Ethics Board on 11/04/2013 with decision number 38. This work was supported by a grant from the Anadolu of University and Research, within the research project 1305F089 / 2016. In this project, samples were taken from vaginal smear of 30 pre-menopausal healthy women between 20-40 years of age. It was also taken into consideration that women did not use antibiotics until the last 2 months.

\section{Genotypic identification of bacteria with $16 \mathrm{~s}$ rRNA sequence analysis}

16s rRNA sequence analysis was performed genotypic identification of the bacteria isolate. The genomic DNA of the isolate was purified using GeneJET genomic DNA purification kit (ThermoFischer Scientific). Obtained genomic DNA was used as template DNA and PCR reaction was performed for 16s rRNA gene locus. 27F 5'-AGAGTTTGATCMTGGCTCAG-3' and 1492R 5'TACGGYTACCTTGTTACGACTT-3' universal primers were used. PCR reaction components include $2.5 \mu \mathrm{L}$ of $10 \mathrm{X}$ TaqBuffer $\left(+\mathrm{KCl}-\mathrm{MgCl}_{2}\right), 2.5 \mu \mathrm{L}$ of $25 \mathrm{mM}$ $\mathrm{MgCl}_{2}, 2.5 \mu \mathrm{L}$ of $2.5 \mathrm{mM}$ dNTP mix, $2.5 \mu \mathrm{L}$ of $2.5 \mathrm{mM}$ $27 \mathrm{~F}$ primer, $2.5 \mu \mathrm{L}$ of $2.5 \mathrm{mM} 1492 \mathrm{R}$ primer, $0.25 \mu \mathrm{L}$ of
Taq polymerase $(5 \mathrm{u} / \mu \mathrm{L}), 11.75 \mu \mathrm{L}$ nuclease-free $\mathrm{ddH}_{2} \mathrm{O}$ and $1 \mu \mathrm{L}$ of template DNA. PCR products obtained from the reaction were screened in $1 \%$ agarose gel. $1492 \mathrm{R}$ and 907R (5'-CCGTCAATTCMTTTRAGTTT-3') primers were used for the sequence analysis of nearly 1400 base pair region (Doi et al., 2013). The sequence analysis of isolate was performed by MedSanTek Laboratory Supplies Trade \& Industry Ltd.

\section{Lactic acid production assay}

The LAB isolate was incubated in the MRS broth medium at $37^{\circ} \mathrm{C} 5 \% \mathrm{CO}_{2}$ for 48 hours. Following incubation, $1 \mathrm{~mL}$ of fresh $\mathrm{LAB}$ culture was transferred to a clean flask and filled up to $100 \mathrm{~mL}$ by sterile $\mathrm{dH}_{2} \mathrm{O} .2-3$ drops of phenolphthalein indicator were added and titrated with $0.1 \mathrm{M} \mathrm{NaOH}$ solution. The amount of $\mathrm{NaOH}$ was recorded. Acid produced by the culture was calculated as percent titrable acidity. Lactic acid amount that the bacteria produced was calculated by the formula below. The study was conducted in duplicate (Demirci, Gündüz, 1994).

Acidity \%: $0.1 \mathrm{~N} \mathrm{NaOH}(\mathrm{mL})$ amount used $\times 0.9 / \mathrm{mL}$

\section{Hydrogen peroxide production assay}

The LAB isolate was incubated in the MRS broth medium at $37^{\circ} \mathrm{C} 5 \% \mathrm{CO}_{2}$ for 48 hours. Following incubation, $5 \mathrm{~mL}$ of $\mathrm{dH}_{2} \mathrm{O}$ was added to $\mathrm{LAB}$ culture and centrifuged at $5000 \mathrm{x}$ rpm for 15 minutes. The supernatant phase following centrifugation was filtered through Whatman no 42 filter paper. $4 \mathrm{~mL}$ of filtrate obtained from filtering process was transferred to a tube. $0.5 \mathrm{~mL}$ sulfuric acid, $0.5 \mathrm{~mL}$ ammonium molybdate and $0.5 \mathrm{~mL}$ potassium iodide were added to the filtrate respectively and mixed thoroughly after each chemical addition. Optical density (OD) was measured by $350 \mathrm{~nm}$ wavelength spectrophotometer for 3 times (Shimadzu, UV-1800). OD values were converted into $\mu \mathrm{g} / \mathrm{mL}$ formulation based on standard curve adjusted previously. The study was conducted in duplicate (Patrick, Wagner, 1949).

\section{Proteolytic activity assay}

The LAB isolate was incubated in $5 \mathrm{~mL}$ non-fat milk liquid medium at $37^{\circ} \mathrm{C} 5 \% \mathrm{CO}_{2}$ for 48 hours. Following incubation, $1 \mathrm{~mL}$ of $\mathrm{dH}_{2} \mathrm{O}$ and $10 \mathrm{~mL}$ of trichloroacetic acid (TCA) were added to the medium respectively, mixed gently, incubated at room temperature for 10 minutes and filtered through Whatman no 1 filter paper. $2.5 \mathrm{~mL}$ of the filtrate was transferred to a separate tube, in which $5 \mathrm{~mL}$ of $\mathrm{Na}_{2} \mathrm{CO}_{3} \cdot \mathrm{Na}_{4} \mathrm{P}_{2} \mathrm{O}_{7}$ solution was added and 
mixed thoroughly. $1.5 \mathrm{~mL}$ of phenol indicator was added and shaken until dark blue color appears. The sample was centrifuged at $8000 \mathrm{x} \mathrm{rpm}$ for 15 minutes. OD of the supernatant was measured by $650 \mathrm{~nm}$ wavelength spectrophotometer for 3 times and the values were recorded, which were converted into $\mu \mathrm{g} / \mathrm{mL}$ formulation based on standard curve adjusted for proteolytic activity. The study was conducted in duplicate (Kıvanç, Yapıcı, 2015).

\section{Auto-aggregation}

The LAB isolate was incubated in the MRS broth medium at $37^{\circ} \mathrm{C} 5 \% \mathrm{CO}_{2}$ for 48 hours. Following incubation, the final concentration was adjusted to $10^{8}$ colony forming unit $(\mathrm{cfu}) / \mathrm{mL}$ with $\mathrm{McF}$ arland Densitometer (DEN-1, Biosan) using phosphate buffer saline (PBS) with $\mathrm{pH}$ 6.2. Microbial suspension was spread on a microscope slide and observed by light microscope (Leica DM500) with 100x magnification. Auto-aggregation test is considered positive if the cells aggregate within 2 minutes. The results were recorded (Pascual et al., 2008).

\section{Co-aggregation}

In this assay, Escherichia coli ATCC 25922 strain was used as test microorganism. The incubation conditions for the LAB isolate was in the MRS broth medium at $37^{\circ} \mathrm{C} 5 \% \mathrm{CO} 2$ for 48 hours and for $E$. coli ATCC 25922 in brain-heart infusion broth (BHI) medium at $37^{\circ} \mathrm{C}$ for 24 hours. Following incubation, the LAB isolate and E. coli ATCC 25922 adjusted to $10^{8} \mathrm{cfu} / \mathrm{mL}$ with McFarland Densitometer (DEN-1, Biosan) in the PBS were transferred to a separate tube and mixed for 15 seconds. Samples from both bacteria were seeded in a 24-well plate and incubated at $37^{\circ} \mathrm{C}$ for 48 hours while shaking gently. Following incubation, samples were taken from each well, Gram stained and samples were examined under light microscope (Leica DM500). Co-aggregation condition of the LAB isolate with E. coli ATCC 25922 was recorded (Pascual et al., 2008).

\section{Hydrophobicity}

The LAB isolate was incubated in the MRS broth medium at $37^{\circ} \mathrm{C} 5 \% \mathrm{CO}_{2}$ for 48 hours. Following incubation, the $\mathrm{LAB}$ culture were centrifuged at 12000 $\mathrm{x} \mathrm{g}, 5^{\circ} \mathrm{C}$ for 5 minutes, washed twice in $0.05 \mathrm{M} \mathrm{K}_{2} \mathrm{HPO}_{4}$ (pH: 6.5) buffer and finally solved in the same buffer. The cell suspension was adjusted to an A560 nm value
(Shimadzu, UV-1800) of 1.0 with the buffer and $3 \mathrm{~mL}$ of the bacterial suspension is transferred to a separate tube. $0.6 \mathrm{~mL}$ of $\mathrm{n}$-hexadecane was added in the tube and mixed for 120 seconds. The two phases were allowed to separate for $0 \mathrm{~h}$ at $37^{\circ} \mathrm{C}$. The aqueous phase was carefully removed and spectrophotometric measurement was performed on A560 nm (Vinderola, Reinheimer, 2003). below:

Hydrophobicity was calculated by the formula

$$
\%=\left(\mathrm{A}_{0}-\mathrm{A}\right) \mathrm{A}_{0} \times 100
$$

$\mathrm{A}_{0}$ : Initial absorbance value; A: Final absorbance value

\section{Identifying acid resistance}

The LAB isolate was incubated in the MRS broth medium at $37^{\circ} \mathrm{C} 5 \% \mathrm{CO}_{2}$ for 48 hours. Following incubation, the LAB culture were inoculated with the MRS broth, in which $\mathrm{pH}$ was adjusted to 2 and 3 by $1 \mathrm{~mol} / \mathrm{L} \mathrm{HCl}$. The MRS broth with $\mathrm{pH} 7.2$ was used as control group. Following incubation, samples were collected at $0,1,2$ and 3-hour time points, diluted serially and $10 \mu \mathrm{L}$ from each sample was inoculated on the petri dishes containing the MRS agar. Petri dishes were incubated at $37^{\circ} \mathrm{C} 5 \% \mathrm{CO}_{2}$ for 48 hours. Following incubation, colonies in the petri dishes were counted and results were recorded as cfu/mL (Claire et al., 2006).

\section{Identifying bile salt resistance}

The LAB isolate was incubated in the MRS broth medium at $37^{\circ} \mathrm{C} 5 \% \mathrm{CO}_{2}$ for 48 hours. Following incubation, the LAB culture was inoculated with the MRS broth medium containing $0.1 \%$ and $0.3 \%$ bile salt. Bile salt free-MRS broth medium was used as control. Following incubation, samples were collected at $0,1,2$ and 3 -hour time points, diluted serially and $10 \mu \mathrm{L}$ from each sample was inoculated on the petri dishes containing the MRS agar. Petri dishes were incubated at $37^{\circ} \mathrm{C} 5 \% \mathrm{CO}_{2}$ for 48 hours. Following incubation, colonies in the petri dishes were counted and results were recorded as $\mathrm{cfu} / \mathrm{mL}$ (Pereira, Gibson, 2002).

\section{Antibiotic susceptibility}

Disc Diffusion Susceptibility Method was applied in order to clarify antibiotic susceptibility of the LAB isolate to various antibiotics. In this study, total of 12 antibiotics including ampicillin, erythromycin, gentamycin, clindamycin, methicillin, metronidazole, oxacillin, 
penicillin, cephalothin, sulfamethoxazole + trimethoprim, tetracycline and vancomycin were tested. The $\mathrm{LAB}$ isolate incubated on the MRS agar medium at $37^{\circ} \mathrm{C} 5 \% \mathrm{CO}_{2}$ for 48 hours was adjusted to $0.5 \mathrm{McF}$ arland Turbidity Standard $\left(10^{8} \mathrm{cfu} / \mathrm{mL}\right)$ in the $0.85 \%$ physiological saline. Microbial suspension was inoculated on Mueller Hinton Agar medium using a swab. Cultured petri dishes were dried for 15 minutes. Antibiotic discs were taken by forceps and placed on surface of petri dish under aseptic conditions. 15 minutes later, they were incubated at $37^{\circ} \mathrm{C} 5 \% \mathrm{CO}_{2}$ for 24 to 48 hours. Zone diameters around the discs were measured, recorded and the results were evaluated. The study was conducted in duplicate (Kaewnopparat et al., 2013).

\section{RESULTS}

Gram staining and catalase test were performed on the isolate obtained from the vagina of a healthy woman. The isolate Gram-positive had catalase-negative activity. Genotypic identification through 16s rRNA sequence analysis suggested that the isolate was Lactobacillus crispatus (Accession number: LC065039.1) with 99\% similarity.

Lactic acid production, hydrogen peroxide production and proteolytic activity of the isolate were recorded as $2.275 \%, 0.334 \pm 0.075 \mu \mathrm{g} / \mathrm{mL}$ and $2.131 \pm 0,000$ $\mathrm{mg} / \mathrm{mL}$ respectively (Table I). Although the isolate had auto-aggregation and co-aggregation activity, it had not hydrophobicity activity (Table II). By the end of 3-hour period, the bacteria protected its viability on the $0.1 \%$ and $0.3 \%$ bile salt conditions and, at $\mathrm{pH} 3$ (Figure I).

The acid and bile salt resistance of $L$. crispatus were determined by colony counting at the end of 0 th, 1 st, 2 nd and 3rd hours. h:hour.

The zone diameters around the antibiotic discs (ampicillin, erythromycin, gentamycin, clindamycin, penicillin, cephalothin, tetracycline and vancomycin discs) were recorded as $36 \mathrm{~mm}, 36 \mathrm{~mm}, 24 \mathrm{~mm}, 38 \mathrm{~mm}$, $38 \mathrm{~mm}, 38 \mathrm{~mm}, 30 \mathrm{~mm}$ and $24 \mathrm{~mm}$, respectively. Zone formation around methicillin, metronidazole, oxacillin and sulfamethoxazole + trimethoprim discs was not observed.

\section{DISCUSSION}

Lactobacillus species have beneficial effects predominate in the vaginal microbiota of healthy women. These bacteria are very important in terms of vaginal ecosystem health protection (Aroutcheva et al., 2001). Lactobacillus species are catalase negative,

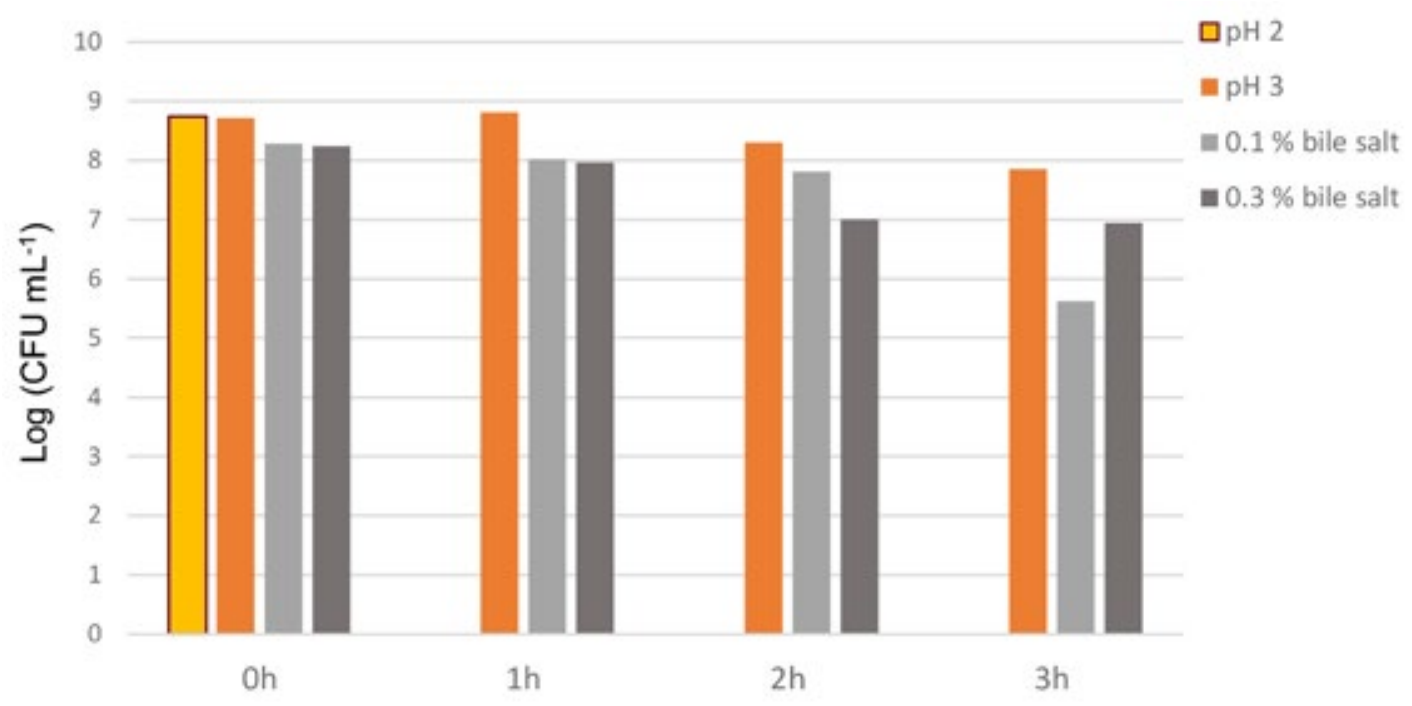

FIGURE 1 - Acid and bile salt resistances of L. crispatus.

TABLE I - The amounts of lactic acid, hydrogen peroxide and proteolytic activity of the L. crispatus

\begin{tabular}{ccc}
\hline$\%$ of Acidity & The amount of hydrogen peroxide $(\boldsymbol{\mu g} / \mathbf{~ m L})$ & Proteolytic activity $(\mathbf{m g} / \mathbf{m L})$ \\
\hline $2.275 \%$ & $0.334 \pm 0.075$ & $2.131 \pm 0.000$ \\
\hline
\end{tabular}

L. crispatus was incubated in the MRS broth medium at $37^{\circ} \mathrm{C} 5 \% \mathrm{CO}_{2}$ for 48 hours. Acid produced by the isolate was calculated as percent titrable acidity. The amount of hydrogen peroxide and proteolytic activity of the isolate were determined by spectrophotometrically. The tests were conducted in duplicate. 
TABLE II - The auto-aggregation, co-aggregation and hydrophobicity activities of the L. crispatus

\begin{tabular}{ccc}
\hline Auto-aggregation & Co-aggregation & Hydrophobicity \\
\hline$(+)$ & $(+)$ & $(-)$ \\
\hline
\end{tabular}

$(+)$ : positive (-): negative. Auto-aggregation of L. crispatus was examined microscopically (Leica DM500). Auto-aggregation test is considered positive if the cells aggregate within 2 minutes. In the co-aggregation assay, E. coli ATCC 25922 strain was used as test microorganism. The coaggregation of L. crispatus with $E$. coli ATCC 25922 was examined microscopically. The amount of hydrophobicity activity of $L$. crispatus were determined by spectrophotometrically.

oxidase negative, gram positive, bacil shaped, facultative aerotolerant, immobilized and non-spore forming bacteria (Hanghshenas et al., 2014).

Previous studies reported that lactic acid bacteria including Lactobacillus acidophilus, L. plantarum, $L$. casei, L. cellobiotus, L. oris, L. reuteri, L. ruminis, $L$. salivarius, L. brevis, L. delbrueckii, L. vaginalis, $L$. gasseri, and L. crispatus are isolated from the vagina of healthy women (Atassi et al., 2006; Kıvanç, Yazıcıoğlu, Dinçer, 2011). In this study, we had isolated L. crispatus from a healthy woman's vagina.

Lactic acid bacteria protect the vagina from pathogens by producing antimicrobials such as lactic acid and bacteriocin (Redondo-Lopez, Cook, Sobel, 1990). The vaginal homeostasis is preserved by lactic acid production of the LABs in the vagina. By the production of organic acids such as lactic acid, vaginal $\mathrm{pH}$ is kept below 4.5. By the acidic nature of the vaginal, the development of pathogen microorganisms is prevented. (Cheeti, Warrier, Lee, 2006). In a study conducted by Aslim and Kilic in 2006 , it was revealed that the amount of acidity in $L$. crispatus strains isolated from healthy women vaginal was $0.48-0.85 \%$ (Aslim, Kilic, 2006). In our study, we monitored that lactic acid production rate of isolated $L$. crispatus was $2.275 \%$.

In vitro experiments indicated that $\mathrm{H}_{2} \mathrm{O}_{2}$ suppress development of endogenous pathogens and various pathogen microorganisms including $G$. vaginalis and HIV (Jespers et al., 2012). In a study conducted by Aslim and Kilic in 2006, it was revealed that although some of L. crispatus strains isolated from healthy women vagina did not produced $\mathrm{H}_{2} \mathrm{O}_{2}$ although some of the L. crispatus strains produced $1.24 \pm 0.02 \mu \mathrm{g} / \mathrm{mL}-3.84 \pm 0.04 \mu \mathrm{g} / \mathrm{mL}$ of $\mathrm{H}_{2} \mathrm{O}_{2}$ (Aslim, Kilic, 2006). Abramov et al. reported that $L$. crispatus 2029 isolated from the healthy women vagina produced $0.120 \pm 0.05 \mu \mathrm{g} / \mathrm{mL}$ of $\mathrm{H}_{2} \mathrm{O}_{2}$ (Abramov et al., 2014). We showed that L. crispatus isolated from the vagina produced $0.334 \pm 0.075 \mu \mathrm{g} / \mathrm{mL}$ of $\mathrm{H}_{2} \mathrm{O}_{2}$. Additionally, L. crispatus' proteolytic activity amount was found $2.131 \pm 0.000 \mathrm{mg} / \mathrm{mL}$. There hasn't been found any study about proteolytic activity of $L$. crispatus isolated from the vagina.

Autoaggregation and coaggregation activities of lactic acid bacteria have great importance (Jankovic et al., 2003). Kmet and Lucchini have shown that 12 of the 60 lactic acid bacteria isolated from vagina have autoaggregation activity (Kmet, Lucchini, 1997). In our study, we found that $L$. crispatus has auto-aggregation activity. It has been reported that Lactobacillus species also have co-aggregation activity with pathogenic bacteria (Reniero et al., 1991). It is clear that they are able to aggregate and co-aggregate with uropathogenic $E$. coli. Kmet and Lucchini have shown that only 3 of 60 lactic acid bacteria isolated from vagina have co-aggregation activity with E. coli strains (Kmet, Lucchini, 1997). Our results also indicated that $L$. crispatus did not co-aggregate with $E$. coli ATCC 25922.

One of the most important features of probiotics is that microorganisms are resistant to low $\mathrm{pH}$ and high bile salts (Brink et al., 2006). Probiotics should be able to tolerate certain conditions such as high bile salt $(0.3 \%)$ and low $\mathrm{pH}(2-3)$ for a minimum of 90 minutes (Hanghshenas et al., 2014). It has been demonstrated that L. crispatus preserved its viability by the end of 3-hour period at $\mathrm{pH} 3$ in our study. Previous studies showed that Lactobacillus crispatus ATCC 33820 strain does not survive more than 2 hours at pH 2 (Pereira, Gibson, 2002).

Bile salts have been reported to be toxic to bacterial cells because of disrupting organization of the cell membrane. Lactic acid has to produce bile salt to survive in the small intestine (Succi et al., 2005). In a study conducted, it was revealed that Lactobacillus lactis ATCC 11454, L. paracasei ATCC 27092, L. casei ATCC 393 ve L. rhamnosus ATCC 53103 strains were able to maintain their viability at the end of the 3 rd hour in $0.4 \%$ bile salt solution (Kaewnopparat et al., 2013). Moreover, L. fermentum SK5 strain can survive in $0.1 \%$ and $0.2 \%$ bile salt conditions (Succi et al., 2005). In our study, we revealed that $L$. crispatus could maintain its viability in $0.1 \%$ and $0.3 \%$ bile salt conditions at the end of the $3 \mathrm{rd}$ hour. Besides, our results indicate that $L$. crispatus did not exhibit hydrophobicity.

In this study, antibiotic susceptibility of $L$. crispatus investigated with disc diffusion method. Total of 12 antibiotics, namely ampicillin, erythromycin, gentamycin, clindamycin, methicillin, metronidazole, oxacillin, penicillin, cephalothin, sulfamethoxazole + trimethoprim, tetracycline and vancomycin were tested. Test results 
revealed that $L$. crispatus showed resistance to methicillin, metronidazole, oxacillin, and sulfamethoxazole + trimethoprim, yet showed susceptibility to ampicillin, erythromycin, gentamycin, clindamycin, penicillin, cephalothin, tetracycline and vancomycin. In a study conducted by Hütt et al. in 2016, it was revealed that all bacteria from 26 L. crispatus strains isolated from vagina showed resistance to metronidazole, kanamycin ve trimethoprim+sulfamethoxazole, although they showed susceptibility to ampicillin, chloramphenicol, eriythromycin, gentamycin, nitrofurantoin, tetracycline and vancomycin. Metronidazole is one of the most commonly used antibiotics in bacterial vaginosis (Ocana, Silva, Nader-Mac' 1as, 2006). In our study, it was observed that our isolate showed metronidazole resistance in agreement with these results.

It has been reported that strains develop resistance to a specific antibiotic may be given with antibiotics during antibiotic treatment (Cebeci, Gürakan, 2003). It has been reported that antibiotic along with LAB strains that are not susceptible to the antibiotic may be given for the protection of microbiota during bacterial vaginosis treatment (Ocana, Silva, Nader-Mac'1as, 2006). Thus, it was observed that the microbiota could regenerate in a shorter time (Cebeci, Gürakan, 2003).

The normal vaginal microbiota has been found to consist primarily of one or more of merely four distinct species, in particular L. crispatus, L. jensenii, L. gasseri, and L. iners (Verstraelen et al., 2009). Lactobacillus crispatus was the most frequent cultured species in vaginal samples. Presence of $L$. crispatus is considered a major determinant to the stability of the normal vaginal microbiota in women of reproductive age (Hütt et al., 2016). Besides, L. crispatus appears to be substantially prevailing over the other hydrogen peroxide producing Lactobacillus species (Abramov et al., 2014). In addition, L. crispatus is a lactic acid bacteria that produces the highest lactic acid when compared to L. iners, L. jensenii, and L. gasseri (Ravel et al., 2011). Lactic acid bacteria in the vagina protects vaginal health by producing antimicrobial agents such as lactic acid and hydrogen peroxide against bacterial pathogens (Hütt et al., 2016).

Lactic acid bacteria that are used as probiotic are beneficial microorganisms (Fuller, 1989). Recently, probiotics are widely used in therapeutic preparations (Shah, 2007). L. crispatus are potential probiotic (Roy et al., 2000). L. crispatus CTV-05 was used as a vaginal suppository for healthy women with a history of recurrent urinary tract infections (Abramov et al., 2014). This study did produce findings that contribute to the probiotic characterization of a L. crispatus strain but it is not yet a readily marketable probiotic product. Our strain promises hope and so further studies are needed to be able to use this strain as a probiotic.

\section{ACKNOWLEDGEMENTS}

This work was supported by a grant from the Anadolu of University and Research, within the research project 1305F089 / 2016.

\section{CONFLICT OF INTEREST}

The authors declare that they have no conflicts of interest.

\section{ETHICAL APPROVAL}

This study was approved by Istanbul Medipol University Non-Interventional Clinical Researches Ethics Board on 11/04/2013 with decision number 38. All applicable international, national, and/ or institutional guidelines for the care and use of human were followed.

\section{REFERENCES}

Abramov V, Khlebnikov V, Kosarev I, Bairamova G, Vasilenko $\mathrm{R}$, Suzina V, et al. Probiotic properties of Lactobacillus crispatus 2,029: homeostatic interaction with cervicovaginal epithelial cells and antagonistic activity to genitourinary pathogens. Probiotics Antimicro Prot. 2014;6(3-4):165-176.

Aroutcheva A, Gariti D, Simon M, Shott S, Faro J, Simoes JA, et al. Defense factors of vaginal lactobacilli. Am J Obstet Gynecol. 2001;185(2):375-379.

Aslim B, Kilic E. Some probiotic properties of vaginal lactobacilli isolated from healthy woman. Jpn J Infect Dis. 2006;59(4):249-253.

Atassi F, Brassart D, Grob P, Graf F, Servin AL. Lactobacillus strains isolated from the vaginal microbiota of healthy women inhibit Prevotella bivia and Gardnerella vaginalis in coculture and cell culture. FEMS Immunol Med Microbiol. 2006;48(3):424-432.

Bergonzelli GE, Blum S, Brussow H, Corthesy-Theulaz I. Probiotics as a treatment strategy for gastrointestinal diseases? Digestion. 2005;72(1):57-68. 
Brink M, Todorov SD, Martin JH, Senekal M, Dicks LMT. The effect of probiotics on production of antimicrobial compounds, resistance to growth at low $\mathrm{pH}$ and in the intestinal mucus. $\mathrm{J}$ Appl Microbiol. 2006;100(4):813-820.

Cebeci A, Gürakan C. Properties of potential probiotic Lactobacillus plantarum strains. Food Microbiol. 2003;20(5):511-518.

Cheeti S, Warrier BK, Lee CH. The role of monocarboxylate transporters in uptake of lactic acid in HeLa cells. Int J Pharm. 2006;325(1-2):48-54.

Claire L, Glenn V, Gibson R, Robert A. Carbohydrate preference, acid tolerance and bile tolerance in five strains of Bifidobacterium. J Appl Microbiol. 2006;100(4):846-853.

Demirci M, Gündüz H. Süt Teknolojisi El Kitabı. Ankara: Hasad Yayıncılık, Ankara; 1994. 184 p.

Doi K, Phuong OTA, Kawatou F, Nagayoshi Y, Fujino Y, Ohshima T. Identification and characterization of lactic acid bacteria 1solated from fermented rice bran product. Adv Microbiol. 2013;3(3):265-272.

FAO/WHO. Regulatory and Clinical Aspects of Dairy Probiotics. Food and Agriculture Organization of the United Nations and World Health Organization Expert Consultation Report. 2001.

Fettweis JM, Serrano MG, Girerd PH, Jefferson KK, Buck GA. A new era of the vaginal microbiome: advances using nextgeneration sequencing. Chem Biodivers. 2012;9(5):965976.

Fuller R. Probiotics in man and animal. J Appl Bacteriol. 1989;66(5):365-378.

Hanghshenas B, Abdullah N, Nami Y, Radiah D, Rosli R, Khosroushahi AY. Different effects of two newly-isolated probiotic Lactobacillus plantarum $15 \mathrm{HN}$ and Lactococcus lactis subsp. lactis 44Lac strains from traditional dairy products on cancer cell lines. Anaerobe. 2014;30:51-59.

Hütt P, Lapp E, Štšepetova J, Smidt I, Taelma H, Borovkova N, et al. Characterisation of probiotic properties in human vaginal lactobacilli strains. Microb Ecol Health Dis. 2016;27(1):30484.
Jankovic I, Ventura M, Meylan V, Rouvet M, Elli M, Zink R. Contribution of aggregation-promoting factor to maintenance of cell shape in Lactobacillus gasseri 4B2. J Bacteriol. 2003;185(11):3288-3296.

Jespers V, Menten J, Smet H, Poradosu S, Abdellati S, Verhelst $\mathrm{R}$, et al. Quantification of bacterial species of the vaginal microbiome in different groups of women, using nucleic acid amplification tests. BMC Microbiol. 2012;12:1-10.

Kaewnopparat S, Dangmanee N, Kaewnopparat N, Srichana T, Chulasiri M, Settharaksa S. In vitro probiotic properties of Lactobacillus fermentum SK5 isolated from vagina of a healthy woman. Anaerobe. 2013;22:6-13.

Kıvanç M, Yapıcı E. Kefir as a probiotic dairy beverage: determination lactic acid bacteria and yeast. Int J Food Engin. 2015;1(1):55-60.

Kıvanç M, Yazıcıoğlu D, Dinçer E. Lactic acid bacteria from the vagina of healthy Turkish women: identification, hydrogen peroxide production. London: World Scientific Publisihing; 2011. p.506-509.

Kmet V, Lucchini F. Aggregation-promoting factor in human vaginal Lactobacillus strains. FEMS Immunol Med Microbiol. 1997;19(2):111-114.

Lepargneur JP, Rousseau V. Protective role of the Doderleïn flora J Gynecol Obstet Biol Reprod. 2002;31(5):485-94.

Ocana V, Silva C, Nader-Mac' 1as ME. Antibiotic susceptibility of potentially probiotic vaginal lactobacilli. Infect Dis Obstet Gynecol. 2006;2006:18182.

Paolillo R, Carratelli CR, Sorrentino S, Mazzola N, Rizzo A. Immunomodulatory effects of Lactobacillus plantarum on human colon cancer cells. Int Immunopharmacol. 2009;9(11):12651271 .

Pascual LM, Daniele MB, Ruiz F, Giardano W, Pajaro C, Barberis L. Lactobacillus rhamnosus L60, a potential probiotic isolated from the human vagina. J Gen Appl Microbiol 2008;54(3):141-148.

Patrick W, Wagner HB. Determination of Hydrogen Peroxide in Small Concentrations. Anal Chem. 1949;21(10):1279-1280.

Pereira DIA, Gibson G. Cholesterol assimilation by lactic acid bacteria and bifidobacteria isolated from the human gut. Appl Environ Microbiol. 2002;68(9):4689-4693. 
Ravel J, Gajer P, Abdo Z, Schneider GM, Koenig SS, McCulle $\mathrm{SL}$, et al. Vaginal microbiome of reproductive-age women. Proc Natl Acad Sci. 2011;108(Suppl 1):4680-4687.

Redondo-Lopez V, Cook RL, Sobel JD. Emerging role of lactobacilli in the control and maintenance of the vaginal bacterial microflora. Rev Infect Dis. 1990;12(5):856-872.

Reniero R, Cocconcelli PS, Bottazzi V, Morelli L. High frequency conjugation in lactobacillus mediated by an aggregation promoting factor. J Gen Microbiol. 1991;138:763-8.

Roy D, Ward P, Vincent D, Mondou F. Molecular identification of potentially probiotic lactobacilli. Curr Microbiol. 2000;40(1):4046.

Shah NP. Functional cultures and health benefits. Int Dairy J. 2007;17(11):1262-1277.
Succi M, Tremonte P, Reale A, Sorrentino E, Grazia L, Pacifico $\mathrm{S}$, et al. Bile salt and acid tolerance of Lactobacillus rhamnosus strains isolated from Parmigiano Reggiano cheese. FEMS Microbiol. 2005;244(1):129-137.

Verstraelen H, Verhelst R, Claeys G, De Backer E, Temmerman M, Vaneechoutte M. Longitudinal analysis of the vaginal microflora in pregnancy suggests that $\mathrm{L}$. crispatus promotes the stability of the normal vaginal microflora and that L. gasseri and/ or L. iners are more conducive to the occurrence of abnormal vaginal microflora. BMC Microbiol. 2009:9(1):116.

Vinderola CG, Reinheimer JA. Lactic acid starter and probiotic bacteria: A comparative in vitro study of probiotic characteristics and biological resistance. Food Res Int. 2003;36(9-10):895-904.

Received for publication on $25^{\text {th }}$ August 2017 Accepted for publication on $02^{\text {nd }}$ May 2018 